DOI: $10.17805 / z p u .2018 .3 .17$

\title{
Влияние чувствительности к человеку на принятие позиций взаимодействия студентами
}

\author{
В. Г. МАРАЛОВ \\ ЧЕРЕПОВЕЦКИЙ ГОСУДАРСТВЕННЫЙ УНИВЕРСИТЕТ, \\ Л. В. РОМАНЮК \\ МОСКОВСКИЙ ГУМАНИТАРНЫЙ УНИВЕРСИТЕТ
}

В статье анализируются психологические особенности влияния чувствительности к человеку на принятие студентами позиций взаимодействия: принуждения, манипулирования, ненасилия, невмешательства. Актуальность проблемы обусловлена значимостью выявления факторов, механизмов и условий формирования у студентов - будущих специалистов сферы психолого-педагогического сопровождения способности к ненасильственному взаимодействию с людьми.

Материалами анализа выступили результаты опроса на выявление уровней выраженности позиций взаимодействия и чувствительности к людям. Были применены методы математической обработки данных, в том числе критерий $\varphi^{*}-$ угловое преобразование Фишера.

В исследовании 2018 г. приняли участие 118 студентов психолого-педагогических специальностей Московского гуманитарного университета и Череповецкого государственного университета. Средний возраст испытуемых - 19,5 года.

Было установлено, что студенты с высоким уровнем чувствительности к человеку чаще принимают позицию ненасилия (63\%), реже - позиции принуждения (25\%) и невмешательства (19\%). Студенты же с низким уровнем чувствительности к человеку чаще принимают позиции невмешательства (59\%) и позицию принуждения (52\%) и практически не используют позицию ненасилия (3\%). Позиция манипулирования не обнаружила существенной связи с уровнями чувствительности к человеку.

Делается вывод о значимости формирования у студентов чувствительности к человеку как фактора, способствующего принятию личностью позиции ненасилия. Полученные результаты могут быть использованы в процессе разработки специальных программ по целенаправленному формированию у студентов - будущих специалистов сферы психолого-педагогического сопровождения способности к ненасильственному взаимодействию.

Ключевые слова: чувствительность к человеку; интерес к человеку; эмпатия; понимание; помощь; позиция принуждения; позиция манипулирования; позиция ненасилия; позиция невмешательства; студенты

* Исследование выполнено при финансовой поддержке РФФИ в рамках научного проекта № 18-013-00151.

The research is financially supported by RFBR within the scientific project No. 18-013-00151. 


\section{ВВЕДЕНИЕ}

$\mathrm{B}$ ступая во взаимодействие друг с другом, люди в зависимости от ориентации на ценности принуждения или ненасилия могут занимать различные позиции: принуждения, манипулирования, ненасилия, невмешательства (Маралов, Ситаров, 2017). Позиция принуждения проявляется в том, что свои цели индивид достигает, используя прямые методы воздействия на противоположную сторону: давление, приказ, требование, подчинение себе, угрозы, агрессивные действия в различных формах. Позиция манипулирования - завуалированная форма принуждения, когда поставленные цели достигаются посредством использования действий манипулятивного характера: лести, обмана, подкупа, запугивания, опосредованного давления и др. Позиция ненасилия предполагает ориентацию личности не только на свои интересы, но и интересы противоположной стороны, когда применяются такие способы воздействия, которые не наносят ущерба: помощь, сотрудничество, просьбы, компромисс и т. А. Позиция невмешательства - пассивная позиция, когда индивид предпочитает вообще не вмешиваться активно в жизненные события.

Способность к ненасильственному взаимодействию является важнейшим показателем профессиональной компетентности специалистов сфер, предполагающих работу с людьми: педагогов, психологов, врачей, социальных работников и т. А. Трудно, например, представить себе психолога, который процесс психологического сопровождения личности строит на основе давления и принуждения, без учета индивидуальных особенностей людей, с которыми он работает. В этом случае необходимо говорить о его профессиональной непригодности. Способность к ненасильственному взаимодействию необходимо формировать уже в вузе в процессе профессиональной подготовки. Особенно это касается будущих учителей, психологов, социальных педагогов, врачей, социальных работников, дефектологов. В соответствии с этим возникает ряд вопросов научного и практического характера. В научном плане принципиальное значение приобретает проблема выявления структуры позиции ненасилия, факторов ее формирования. В практическом плане особую актуальность приобретают вопросы, связанные с созданием психолого-педагогических условий в вузах, благоприятных для развития у студентов способности к ненасильственному взаимодействию.

Можно выделить ряд факторов, оказывающих наиболее существенное влияние на принятие людьми той или иной позиции взаимодействия. К ним мы относим раздражительность к людям, стереотипность, способность к принятию другого человека, терпимое отношение к нему, эгоцентризм или его отсутствие, уровень доверия к другим и к себе, специфическую чувствительность к человеку и другие (Маралов, Ситаров, 2016). В предыдущем нашем исследовании была показана роль раздражительности к людям и социально-педагогических стереотипов в выборе позиций взаимодействия (Maralov, Sitarov 2018).

В частности, было установлено, что высокий уровень раздражительности к людям способствует принятию позиции принуждения, а приверженность стереотипам обусловливает принятие позиции невмешательства.

Мы полагаем, что особую роль в принятии индивидом позиции ненасилия играет феномен чувствительности к человеку, под которой мы понимаем его способность выделять других людей в качестве значимых субъектов взаимодействия, делать их объектом своего внимания, не испытывая при этом к ним антипатий или безразличия. Чувствительность к человеку находит свое конкретное выражение в таких 
понятиях, как чуткость, внимательность к людям, доброжелательность, отзывчивость, в противовес равнодушию, безразличию, черствости, холодности, невосприимчивости.

Цель настоящего исследования состояла в выявлении психологических особенностей влияния чувствительности к человеку на принятие позиций взаимодействия. Мы исходили из предположения о том, что высокий уровень чувствительности к человеку будет положительно сказываться на стремлении человека взаимодействовать с другими людьми на ненасильственной основе. Низкий же уровень чувствительности, наоборот, будет способствовать принятию позиции принуждения или, по крайней мере, позиции невмешательства. Если это предположение подтвердится, то со всей обоснованностью можно будет утверждать о важности работы по формированию у студентов чувствительности к человеку как профессионально значимого качества личности.

В качестве конкретных задач исследования выступили следующие: осуществить теоретический анализ проблемы чувствительности к человеку в современной психологии; на основе эмпирических данных дать общую характеристику выраженности позиций взаимодействия, а также отдельных параметров и обобщенного показателя чувствительности к человеку у студентов - будущих специалистов сферы психологопедагогического сопровождения; выявить психологические особенности взаимосвязи чувствительности к человеку и выраженности позиций взаимодействия у студентов.

\section{ОБЗОР АИТЕРАТУРЫ}

Термин «чувствительность» (сензитивность) широко используется в современной психологии. Говорят о сензитивности как о свойстве темперамента (Мерлин, 1964), как о типе характера (Минияров, 2000). Выделяют социальную чувствительность (Юсупов, 1995), этическую чувствительность (Rest, 1986), чувствительность к проблемам (Бакурова, 2015), чувствительность к опасностям (Маралов и др., 2013) и др.

С позиций рассматриваемой проблемы для нас особый интерес представляет социальная и этическая чувствительность.

Под социальной чувствительностью понимается повышенная чувствительность к происходящим событиям. И. М. Юсупов выделяет и описывает четыре вида социальной чувствительности: наблюдательную, номотетическую, идеографическую и теоретическую сензитивность (Юсупов, 1995). Наблюдательная сензитивность проявляется в способности фиксировать при наблюдении за человеком его поведение: мимику, пантомимику и др., адекватно отражать их во взаимодействии. Номотетическая сензитивность - способность понимать представителя той или иной социальной группы. Идеографическая сензитивность, наоборот, проявляется в способности фиксировать индивидуальные особенности личности. Теоретическая сензитивность выражается в умении выбирать и применять теории для более точного предсказания чувств, мыслей и действий других людей.

Понятие этической (моральной) чувствительности было введено в психологический обиход Аж. Рестом (Rest, 1986). Моральная чувствительность определяется автором как осознание человеком того, как его действия могут повлиять на других людей. Это «осознание» включает в себя знание о том, кто является участником ситуации морального выбора; конструирование возможных вариантов поведения в указанной ситуации; представление о том, какое влияние предпринятые действия окажут на разных участников ситуации. 
Конструкт «этическая чувствительность» широко используется в современных исследованиях. Изучается роль этической чувствительности в различных сферах жизнедеятельности человека. В частности, предпринимаются попытки выявить конкретные механизмы этической чувствительности (Weaver, 2005), исследуется влияние нормативных, организационных и личностных факторов на этическую чувствительность (Patterson, 2001), показывается зависимость этической чувствительности от профессионального опыта человека (Fleck-Henderson, 1996), изучается роль этической чувствительности в принятии управленческих решений (Wittmer, 1993).

Чувствительность к человеку имеет свою структуру. Мы полагаем, что в качестве ее важнейших компонентов выступают интерес к человеку, эмпатия, понимание и помощь (Маралов, Маралова, 2009). Остановимся на характеристике этих компонентов подробнее.

Интерес к человеку. Как известно, интерес - это эмоционально окрашенная познавательная потребность. Следовательно, интерес к человеку есть эмоционально окрашенная потребность в познании «Аругого». Существуют люди, у которых «Аругие» не вызывают особого интереса, особенно те люди, которые не входят в их ближний круг. Взаимодействие с ними осуществляется в силу необходимости. По большому счету люди им безразличны, поэтому они испытывают к ним равнодушие. Е. П. Ильин (Ильин, 2013) определяет равнодушие как состояние апатии к окружающему миру, людям, событиям, отсутствие беспокойства о других людях. Автор выделяет различные причины равнодушия. Оно может возникать в результате привыкания к фактам несправедливости, насилия, беззакония, может выступать в качестве психологической защиты, являться следствием алекситимии (неспособности словесно описать свои эмоции и эмоции других людей), результатом несформированности механизмов идентификации и эмпатии и др.

В то же время немало и таких людей, для которых практически любой человек представляет интерес, загадку, что стимулирует желание взаимодействовать, общаться, стремление к познанию и пониманию его. Интерес к человеку является важным мотивом деятельности в профессиях типа «человек - человек». Трудно себе представить педагога, которому не интересны дети, психолога, которому не интересны клиенты, врача, которому безразличны больные, обратившиеся к нему за помощью. Несмотря на значимость феномена интереса к людям для теории и психологической практики, специальных работ, в которых бы затрагивались проблемы интереса к человеку, не так много. Тем не менее они имеются. Например, Е. Н. Кузнецова специально занималась проблемой формирования интереса к человеку у студентов - будущих педагогов (Кузнецова, 2010). Под интересом к человеку она понимает позитивно окрашенное ценностное отношение к человеку; избирательную направленность на человека; познавательную потребность, предметом которой является человек. У И. В. Сиволобовой интерес к человеку описывается через понятие ценностной ориентации на человека, в основе которой лежат такие категории, как достоинство, ответственность, уважение, сочувствие, содействие (Сиволобова, 2002).

Эмпатия. Важнейшей характеристикой чувствительности к человеку является эмпатия, которая проявляется в способности входить «в резонанс» с другим человеком, эмоционально сочувствовать и сопереживать ему. Не случайно К. Роджерс определил эмпатию как умение «быть с другим человеком», тонко реагировать на все изменения, происходящие в нем, оставаясь при этом самим собой (Роджерс, 2002). В современной психологии накоплен богатейший материал относительно эмпатии, механизмов ее 
проявления, особенностей формирования. Чаще всего в психологии выделяют две формы әмпатии: сопереживание и сочувствие (Гаврилова, 1974). Сопереживание, иными словами, совместное переживание, проявляется в переживании тех же чувств, которые испытывает другой человек. Сочувствие - это уже отношение одного человека к другому как проявление участия и отзывчивости. В последующем была выделена еще одна форма эмпатии - содействие (Стрелкова, 1987), в котором находит выражение активная сторона эмпатии. И. М. Юсупов отмечает, что содействие выступает в качестве высшего ругулятивного компонента эмпатии как синтез эмоциональной, когнитивной и поведенческой ее сторон (Юсупов, 1995). В настоящее время предпринимаются попытки выделить и описать различные виды эмпатии: внешнюю, внутреннюю, компенсаторную, дезинтеграционную, дефицитарную, ложную и истинную (Аорошенко, 2007).

Понимание. Понимание в психологии - это операция мышления, посредством которой человек включает новое знание в свой прошлый опыт, в свою устоявшуюся систему представлений о мире. В отечественной психологии одним из первых проблемой понимания человека человеком стал заниматься А. А. Бодалев, который рассматривает понятие о другом человеке как форму мышления, в которой обобщенно фиксируются признаки данного человека, характеризующие его как субъекта различных видов деятельности и общения (Бодалев, 1982). Понимание другого человека включает в себя способность не только отображать эмоциональные и поведенческие особенности человека, но и видеть причины, обусловливающие те или иные личностные и поведенческие характеристики. Как отмечает Н. И. Шевандрин, понимание другого осуществляется посредством объяснения, интерпретации, умения вживаться во внутренний мир другого (Шевандрин, 1998).

Понимание - наиболее сложный процесс, который требует от личности не только актуализации своих интеллектуальных возможностей, но и собственного опыта, интуиции. Способность к быстрому и полному проникновению во внутренний мир другого человека получила название психологической проницательности, под которой имеется в виду целостное, интегративное свойство человека, включающее в себя ряд качеств, благодаря которым познается внутренний мир других людей (Есманская, 2007).

Помощь. Помощь - это деятельностный компонент проявления чувствительности к человеку. Под помощью понимают совокупность действий, осуществляемых индивидом с целью «возвращения» объекта помощи в исходное состояние или состояние лучшее, чем исходное. Помощь может оказываться как по инициативе нуждающегося в ней, так и по инициативе самой личности, которая добровольно готова предоставить ее другому человеку. Мотивы оказания помощи многообразны. Как показал Х. Хекхаузен, проявления помогающего поведения обусловлены двумя группами мотивов: мотивами морального долга и мотивами морального сочувствия (Хекхаузен, 2003). Существуют различные виды оказания помощи: физическая, материальная, моральная, интеллектуальная. С содержательной точки зрения наиболее распространенным видом помощи является забота о другом человеке, под которой понимается активность, направленная на содействие чьему-либо благу (Ильин, 2013).

Все компоненты чувствительности к человеку тесно связаны между собой. Этот факт хорошо фиксирует современная психология.

Например, И. Г. Ааверычева чувствительность к человеку рассматривает в качестве фактора, предшествующего эмпатии (в нашей концепции эту функцию выполняет 
интерес к человеку), и определяет ее как остроту восприятия личности другого человека (Иаверычева, 2013). Интегрируясь с эмпатией, она начинает выступать уже как человекочувствительность. Наибольшее число работ посвящено вопросам интеграции эмпатии и понимания. Благодаря К. Роджерсу в науке широкое распространение получил термин «эмпатическое понимание». В качестве механизмов такого понимания выступают способность к эмоционально-когнитивной децентрации субъекта и его идентификация с эмпатируемым объектом (Юсупов, 1995). Инструментом, позволяющим распознавать состояния другого человека, принимать на этой основе решения, является эмоциональный интеллект, под которым понимают способность отслеживать собственные и чужие чувства и эмоции, различать их и использовать эту информацию для направления мышления и действий (Salovey, Mayer, 1990). Современная структура эмоционального интеллекта включает в себя осознанную регуляцию эмоций, понимание (осмысление) эмоций, ассимиляцию эмоций и мышления, различение и выражение эмоций (Андреева, 2006).

Интеграция эмпатии и помощи проявляется в содействии. Как мы уже отметили, в отечественной психологии содействие как компонент эмпатии был введен А. П. Стрелковой (Стрелкова, 1987). Согласно автору, әмпатический процесс представляет цепочку: сопереживание - сочувствие - содействие. Отмечается, что если сопереживание носит чисто эмоциональный характер, то сочувствие уже включает в себя и когнитивный компонент. Сочувствие и анализ ситуации вызывают импульс к помогающему поведению, т. е. содействию.

Итак, мы попытались в общих чертах описать чувствительность к человеку и компоненты, ее составляющие. Названные компоненты могут иметь различную степень сформированности и по-разному сочетаться у людей. Например, у индивида может быть на высоком уровне интерес к человеку, не подкрепленный способностью к эмпатии и к помощи. Он отражает лишь простое любопытство к людям, поверхностное понимание, и не более того. И наоборот, при относительно низком интересе в определенных ситуациях вполне возможны проявлении и эмпатии, и понимания, и помощи.

В современной науке имеется немало исследований, которые раскрывают роль чувствительности к человеку в организации и построении взаимодействия, принятии той или иной позиции. Исследования показывают, что высокий уровень чувствительности к человеку способствует формированию просоциальной ориентации, низкий уровень - обусловливает эгоцентрическую ориентацию (Юсупов, 1995). В то же время имеются работы, в которых вносятся существенные коррективы в эту закономерность. Так И. Г. Ааверычева выявила, что высоким уровнем эмпатии могут обладать как альтруисты, так и эгоисты (Ааверычева, 2013). Чтобы осуществился акт помогающего поведения, необходим перенос состояний человека, нуждающегося в помощи и поддержке, на себя. Т. В. Аорошенко наряду с истинной эмпатией выделяет внешнюю эмпатию, которую человек демонстрирует потому, что так принято, соответствует нормативному поведению (Аорошенко, 2007). Возможно также проявление ложной эмпатии, которая используется с целью манипулирования личностью. Таким образом, анализируя своеобразие проявлений высокой чувствительности к человеку, необходимо знать ту мотивацию, под влиянием которой эта чувствительность осуществляется. Одно дело, когда такая чувствительность формируется под влиянием альтруистических мотивов, другое - когда в ее основе лежит не заинтересованность в человеке и искреннее желание помочь, а преследование собственной выгоды и ожидания «награды». 
Имеются также исследования, которые раскрывают взаимосвязь чувствительности к человеку с характером построения взаимодействия. И. Ю. Зудилина изучала особенности интеракций у студентов с различными социально-психологическими типами (Зудилина, 2014). Было установлено, что для студентов сензитивного социально-психологического типа характерны такие проявления, как самокоррекция, саморефлексия, осознание степени значимости поступков других. Это свидетельствует о способности представителей данного типа гибко выстраивать отношения, быть комфортным партнером при взаимодействии. Показано влияние чувствительности и на профессиональное общение. Так, Е. А. Писаревой, Е. В. Зиновьевой, С. Н. Костроминой установлено, что начинающие психологи-консультанты, отличающиеся консервативностью, нечувствительностью, ригидностью, склонны оценивать своих клиентов как сопротивляющихся терапии и испытывают к ним чувство презрения и раздражения (Писарев, Зиновьева, Костромина, 2016).

Подводя итоги обзору литературы, необходимо констатировать, что чувствительность к человеку и различные ее компоненты достаточно всесторонне исследуются в современной науке. Выявлен ряд закономерностей, которые позволяют понять в целом суть данного феномена. В то же время нами практически не было обнаружено работ, в которых бы чувствительность к человеку изучалась в качестве фактора принятия людьми той или иной позиции взаимодействия, что послужило дополнительным стимулом к организации и проведению специального исследования, посвященного этой проблеме.

\section{МАТЕРИААЫ И МЕТОАЫ}

В процессе исследования были использованы следующие методы: теоретические анализ; конкретизация; обобщение; эмпирические - опросники на выявление уровней выраженности позиций взаимодействия и чувствительности к людям; методы математической обработки данных - использовался критерий $\varphi^{*}$ - угловое преобразование Фишера.

Опросник по выявлению у студентов уровня выраженности позииий взаимодействия (Маралов, Ситаров, 2017). Состоит из 40 вопросов-утверждений, по 10 вопросов на каждую позицию: принуждения, манипулирования, ненасилия, невмешательства. Испытуемым предлагались вопросы и по четыре варианта ответов на каждый из них, из которых им нужно было выбрать только один. За итоговый результат принималась сумма баллов, набранная каждым испытуемым по каждой шкале.

Опросник по выявлению уровня выраженности чувствительности к человеку (Маралов, Маралова, 2009). Состоит из 20 вопросов-утверждений, по 5 вопросов на каждый структурный компонент чувствительности к человеку: интерес к человеку; эмпатия; понимание; помощь. Оценивались как отдельные компоненты чувствительности, так и находился обобщенный индекс чувствительности к человеку.

Всего в исследовании приняли участие 118 студентов - будущих специалистов сферы психолого-педагогического сопровождения Московского гуманитарного университета (70 человек) и Череповецкого государственного университета (48 человек). Средний возраст испытуемых - 19,5 года. Обследование студентов проводилось в 2018 г.

Исследование проводилось в три этапа. На первом этапе осуществлялся теоретический анализ проблемы, были выделены и описаны основные характеристики чувствительности к человеку. На втором этапе было осуществлено эмпирическое исследо- 
вание влияния чувствительности к человеку на уровень выраженности позиций взаимодействия. Третий этап был посвящен обработке полученных данных, обсуждению результатов, подведению итогов.

\section{РЕЗУ}

Обратимся к основным результатам исследования. В первую очередь дадим общую характеристику выборки испытуемых по параметрам выраженности позиций взаимодействия и выраженности чувствительности к человеку. Уровни выраженности позиций принуждения, манипулирования, ненасилия и невмешательства у студентов приведены в табл. 1. Высокий уровень выраженности той или иной позиции означает, что индивид предпочитает в ходе разрешения своих проблем использовать, например, принуждение или любую другую позицию. Средний уровень свидетельствует об эпизодическом использовании принуждения (манипулирования, ненасилия, невмешательства). Низкий уровень - о достаточно редком использовании той или иной позиции.

УРОВНИ ВЫРАЖЕННОСТИ ПОЗИЦИЙ ВЗАИМОАЕЙСТВИЯ У СТУАЕНТОВ

Таблица 1

Table 1

LEVELS OF MANIFESTATION OF INTERACTION POSITION AMONG STUDENTS

\begin{tabular}{|c|c|c|c|c|c|c|c|c|}
\hline \multirow{2}{*}{ Уровни } & \multicolumn{2}{|c|}{$\begin{array}{c}\text { Позичия } \\
\text { принуждения }\end{array}$} & \multicolumn{2}{|c|}{$\begin{array}{c}\text { Позичия } \\
\text { манипулирования }\end{array}$} & \multicolumn{2}{|c|}{$\begin{array}{l}\text { Позичия } \\
\text { ненасилия }\end{array}$} & \multicolumn{2}{|c|}{$\begin{array}{c}\text { Позичия } \\
\text { невмешательства }\end{array}$} \\
\hline & число & прочент & число & прочент & число & прочент & число & прочент \\
\hline Высокий & 52 & 44 & 34 & 29 & 32 & 27 & 34 & 29 \\
\hline Средний & 36 & 31 & 47 & 40 & 51 & 43 & 49 & 41 \\
\hline Низкий & 30 & 25 & 37 & 31 & 35 & 30 & 35 & 30 \\
\hline Всего & 118 & 100 & 118 & 100 & 118 & 100 & 118 & 100 \\
\hline
\end{tabular}

Как видно из табл. 1, высокий уровень выраженности позиции принуждения наблюдается у 44\% испытуемых, средний уровень - у 31\%, низкий уровень - у 25\% испытуемых. Позиция манипулирования на высоком уровне проявляется у 29\% студентов, на среднем уровне у 40\%, на низком - у $31 \%$ студентов. Позиция ненасилия на высоком уровне проявляется у $27 \%$, на среднем уровне - у $45 \%$, на низком уровне у $30 \%$ испытуемых. Наконец, позиция невмешательства на высоком уровне выражена у $29 \%$ студентов, на среднем уровне - у 41\% и на низком - у $30 \%$. Таким образом, все позиции у студентов представлены достаточно равномерно, нельзя сказать, что в целом по выборке какая-то одна из названных позиций занимает доминирующее положение. Понятно, что для исследования и последующей интерпретации результатов принципиальное значение имеет только высокий уровень выраженности той или иной позиции.

Следует также обратить внимание и на тот факт, что у одного и того же человека могут доминировать как одна, так и несколько позиций вплоть до противоречивого их сочетания. Например, в одних случаях индивид отдает предпочтение принуждению или манипулированию, в других - ненасилию. Исследование показало, что позиции 
принуждения отдает предпочтение 9\% испытуемых, позиции принуждения и манипулирования - 17\% студентов. Чистых манипуляторов обнаружилось совсем немного, они составили всего 1\%. Позиция ненасилия доминирует у $16 \%$ студентов, а позиция ненасилия в сочетании с позицией невмешательства - у 6\%. Высокий уровень выраженности позиции невмешательства также обнаружен у 6\% испытуемых. Наиболее часто встречается противоречивое сочетание позиций, например, принуждения и ненасилия, манипулирования и ненасилия и др. Такое сочетание обнаружено у $23 \%$ студентов. Наконец, у достаточно большого числа студентов (22\%) ни одна из названных позиций не занимает доминирующего положения. Иными словами, их поведение не отличается последовательностью и четкостью обозначения позиций.

Обратимся к анализу отдельных компонентов чувствительности человека. Как это было обозначено в теоретической части статьи, к ним относятся интерес к людям, эмпатия, понимание и помощь. Распределение испытуемых по уровням выраженности отдельных компонентов чувствительности к человеку приведено в табл. 2.

Таблица 2

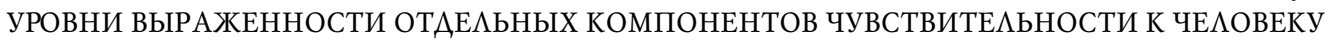
У СТУАЕНТОВ

Table 2

LEVELS OF MANIFESTATION OF SEPARATE COMPONENTS OF HUMAN-SUSCEPTIBILITY AMONG STUDENTS

\begin{tabular}{|l|c|c|c|c|c|c|c|c|}
\hline \multirow{2}{*}{ Уровни } & \multicolumn{2}{|c|}{$\begin{array}{c}\text { Интерес } \\
\text { кчеловеку }\end{array}$} & \multicolumn{2}{|c|}{ Элпатия } & \multicolumn{2}{c|}{ Понимание } & \multicolumn{2}{c|}{ Помошь } \\
\cline { 2 - 9 } & число & прочент & чсло & прочент & число & прочент & число & прочент \\
\hline Высокий & 43 & 36 & 53 & 45 & 27 & 23 & 62 & 52 \\
Средний & 40 & 34 & 35 & 30 & 49 & 41 & 29 & 25 \\
Низкий & 35 & 30 & 30 & 25 & 42 & 36 & 27 & 23 \\
Всего & 118 & 100 & 118 & 100 & 118 & 100 & 118 & 100 \\
\hline
\end{tabular}

Опишем результаты исследования, представленные в табл. 2. Интерес к человеку на высоком уровне проявляется у $36 \%$ испытуемых, на среднем - у 34\%, на низком у $30 \%$. Высокий уровень эмпатии способны демонстрировать $45 \%$ студентов, средний уровень - 30\%, низкий уровень - 25\%. Хуже дело обстоит с пониманием человека. Считают, что способны хорошо понимать других людей, 23\% студентов, на среднем уровне - 41\%, и плохо понимают других - 36\% испытуемых. Высокий уровень стремления прийти другим на помощь проявляется у $52 \%$ студентов, средний уровень помощи - у $25 \%$, практически отказываются от оказания помощи другим $23 \%$.

Полученные результаты наглядно демонстрируют тот факт, что в большей степени у студентов проявляется такой компонент чувствительности к человеку, как способность оказывать помощь (52\%). На втором месте стоит эмпатия (45\%) и интерес к людям (36\%). Третью позицию занимает понимание других (23\%). Такая ситуация вполне закономерна и объяснима. Посочувствовать человеку или оказать ему посильную помощь легче, чем понять его внутренний мир, мотивы поведения и поступков, намерения и планы. У студентов же, хотя они и выбрали направления подготовки и специальности, связанные с человекознанием, еще мал собственный опыт общения 
и взаимодействия с людьми, поэтому в ряде ситуаций им достаточно трудно понять другого человека, правильно интерпретировать его мысли, действия и поведение.

Обобщенный индекс чувствительности к человеку для каждого испытуемого вычислялся как сумма баллов, набранная по каждому отдельному компоненту. Максимальное значение по каждому параметру равно 5 баллам, минимальное - 0 баллов. Следовательно, каждый испытуемый может набрать в итоге от 0 до 20 баллов. Аалее все испытуемые по сумме набранных баллов были ранжированы и разбиты на три группы. Примерно по $25 \%$ составили студенты с высоким и низким уровнем чувствительности, и 50\% были отнесены к среднему уровню. В итоге получилось, что к высокому обобщенному показателю чувствительности к человеку были отнесены испытуемые, у которых практически все компоненты оказались на высоком уровне или по крайней мере три из четырех. К низкому обобщенному показателю чувствительности - студенты с низким уровнем выраженности всех компонентов чувствительности. Остальные студенты составили группу со средним уровнем чувствительности к человеку.

Обратимся теперь к решению основной задачи настоящего исследования - выявлению особенностей взаимосвязи чувствительности к человеку с позициями взаимодействия. В качестве показателей выраженности позиций взаимодействия взяты только высокие значения признака (высокий уровень выраженности позиций, как это отражено в табл. 1). Статистическая значимость различий в крайних группах испытуемых (с высоким и низким уровнем чувствительности) осуществлялась с помощью критерия $\varphi^{*}$ - углового преобразования Фишера. Результаты отражены в табл. 3.

Таблица 3

ВАИЯНИЕ ЧУВСТВИТЕАЬНОСТИ К ЧЕАОВЕКУ

НА ВЫРАЖЕННОСТЬ ПОЗИЦИЙ ВЗАИМОАЕЙСТВИЯ У СТУАЕНТОВ

Table 3

THE INFLUENCE OF HUMAN-SUSCEPTIBILITY

ON STUDENTS' MANIFESTATION OF INTERACTION POSITIONS

\begin{tabular}{|c|c|c|c|c|c|c|c|}
\hline \multirow{3}{*}{ Позиции } & \multicolumn{6}{|c|}{ Уровни чувствительности к человеку } & \multirow{3}{*}{$\begin{array}{c}\text { Статистическая значимость } \\
\text { различий в группах с высокой и } \\
\text { низкой чувствительностью к че- } \\
\text { ловеку (критерий ф* -угловое } \\
\text { преобразование Фишера) }\end{array}$} \\
\hline & \multicolumn{2}{|c|}{ высокий } & \multicolumn{2}{|c|}{ средний } & \multicolumn{2}{|c|}{ низкий } & \\
\hline & $n$ & $\%$ & $n$ & $\%$ & $n$ & $\%$ & \\
\hline Принуждения & 8 & 25 & 29 & 51 & 15 & 52 & $\varphi^{*}=2,20$, при р I 0,05 \\
\hline Манипулирования & 7 & 22 & 19 & 33 & 8 & 28 & $\varphi *=0,54$, не значимо \\
\hline Ненасилия & 20 & 63 & 11 & 19 & 1 & 3 & $\varphi^{*}=5,80$, при р I 0,001 \\
\hline Невмешательства & 6 & 19 & 10 & 18 & 17 & 59 & $\varphi^{*}=3,32$, при р I 0,001 \\
\hline $\begin{array}{l}\text { Всего по уровням } \\
\text { чувствительности: }\end{array}$ & 32 & 27 & 57 & 48 & 29 & 25 & \\
\hline
\end{tabular}

Результаты, приведенные в табл. 3, достаточно иллюстративны. Использование принуждения обратно пропорционально уровню чувствительности. Если среди студентов с высоким уровнем чувствительности к человеку только $25 \%$ используют принуждение для решения своих задач, то уже у студентов со средним уровнем чувствительности этот процент возрастает в 2 раза (51\%) и сохраняется примерно на том же уровне $(52 \%)$ у студентов с низкой чувствительностью к человеку. Различия статисти- 
чески значимы ( $\varphi^{*}=2,20$, при p I 0,05). Примерно такую же картину мы наблюдаем и относительно позиции невмешательства.

Среди испытуемых с высоким уровнем чувствительности к человеку позицию невмешательства использует 19\% респондентов. Этот процент практически сохраняется в группе со средним уровнем чувствительности $(18 \%)$ и резко возрастает до $59 \%$ у студентов с низкой чувствительностью к человеку. Различия в крайних группах статистически значимы $(\varphi *=3,32$, при р I 0,001).

Что касается позиции ненасилия, то здесь мы наблюдаем прямую положительную связь. Чем выше чувствительность к человеку, тем предпочтительнее оказывается использование ненасилия в процессе взаимодействия. 63\% испытуемых с высокой чувствительностью к человеку предпочитают действовать ненасильственно. Этот процент значительно снижается (до 19\%) у испытуемых со средним уровнем чувствительности к человеку и сходит практически на нет $(1 \%)$ у студентов с низкой чувствительностью. Различия в крайних группах статистически значимы ( $\varphi^{*}=5,80$, при р I 0,001).

Позиция манипулирования не претерпевает таких существенных изменений. В группе студентов с высоким уровнем чувствительности она проявляется у 22\% испытуемых, со средним уровнем - у 33\%, с низким уровнем - у 28\%. Различия статистически не значимы. Это позволяет сделать вывод о том, что стремление манипулировать не зависит прямо от уровня чувствительности к человеку, а определяется, вероятно, другими факторами.

Таким образом, можно заключить, что чувствительность к человеку оказывает в целом существенное влияние на принятие личностью той или иной позиции взаимодействия. Высокая чувствительность создает благоприятные предпосылки для принятия позиции ненасилия. Низкая же чувствительность, наоборот, стимулирует стремление личности к использованию либо принуждения, либо невмешательства в ходе событий.

\section{ОБСУЖАЕНИЕ РЕЗУАЬТАТОВ И ЗАКАЮЧЕНИЕ}

Итак, на основании проведенного исследования со всей очевидностью можно утверждать, что формирование у студентов - будущих специалистов сферы психолого-педагогического сопровождения высокой чувствительности к человеку выступает в качестве важнейшего условия принятия ими позиции ненасилия и в постепенном отказе от принуждения и манипулирования. Было показано, что низкая чувствительность к человеку стимулирует стремление либо не вмешиваться в ход событий, безразличие ко всему (59\%), либо решать свои задачи посредством принуждения (52\%) или манипулирования другими (28\%).

Высокий уровень чувствительности проявляется в том, что окружающие люди становятся значимыми для индивида. Он подмечает особенности их поведения и эмоциональных состояний, пытается понять внутренний мир. Аюбой человек ему интересен, он хочет узнать о нем как можно больше. В результате старается выстраивать отношения с ним на принципах сотрудничества и ненасилия. Высокая чувствительность к человеку характеризуется также тем, что индивид не только реагирует на состояние другой личности и оказывает помощь тогда, когда о ней просят, но и инициативно, подчиняясь своим внутренним побуждениям.

Аля индивида с низким уровнем чувствительности другие люди, кроме небольшого круга, не вызывают интереса, потребности выстраивать с ними доверительные отношения. Он просто не задумывается о внутреннем мире другого, его чувствах и пе- 
реживаниях. Такой индивид может проявить эмпатию, но только в том случае, когда это будет касаться только близких людей. Он может оказать помощь, но только тогда, когда его об этом попросят, и никогда по собственной инициативе. Это и порождает в ряде случаев стремление занимать позицию невмешательства, а в эмоционально напряженных или конфликтных ситуациях - позицию принуждения.

Проведенное нами исследование высветило и ряд вопросов, которые требуют обсуждения. Во-первых, чем можно объяснить тот факт, что определенная категория студентов вне зависимости от своего отношения к людям и чувствительности к ним предпочитает манипулирование иным способам решения своих задач? Во-вторых, требует пояснения вопрос о том, почему студенты с высоким уровнем чувствительности к человеку хотя и реже, но все-таки используют принуждение в ходе взаимодействия с другими людьми (25\%).

Аело в том, что многие люди используют манипулирование неосознанно, они не относят его к формам принуждения. Типичное рассуждение манипулятора звучит следующим образом: «Я же не делаю человеку плохо, не наношу ему вреда, я просто хочу добиться своих целей, решить свои задачи». Поэтому манипулировать могут люди и с высокой, и с низкой чувствительностью к человеку.

Принятие же в ряде случаев позиции принуждения людьми с высоким уровнем чувствительности к человеку объясняется незнанием и неспособностью индивида в том или ином конкретном случае найти другие, более эффективные способы взаимодействия. Это ставит в качестве специальной задачи исследование не только чувствительности к человеку, но и других психологических факторов. К ним мы относим: осознание уровня раздражительности, приверженность социальным стереотипам, эгоцентризм, использование различных психологических защит, принятие себя и другого человека. И конечно же, обязательным условием является обучение навыкам и приемам ненасильственного взаимодействия.

Подводя итоги проведенному исследованию, можно сделать следующие выводы.

Теоретический анализ специальной литературы показал, что в качестве одного из важнейших факторов, обусловливающих характер межличностного взаимодействия людей, выступает чувствительность к человеку, под которой понимается способность индивида выделять других людей в качестве значимых субъектов взаимодействия, делать их объектом своего внимания, не испытывая при этом к ним антипатий или безразличия. Чувствительность к человеку - многогранное явление, проявляющееся в интересе к человеку, эмпатии, стремлении понять его и оказывать в случае необходимости помощь.

Исследование показало, что уровень чувствительности к человеку оказывает существенное влияние на принятие студентами позиций взаимодействия.

Было установлено, что студенты в ходе взаимодействия могут занимать различные позиции: принуждения, манипулирования, ненасилия и невмешательства. Изучение структурных компонентов чувствительности к человеку показало, что в большей степени у студентов выражены такие компоненты, как помощь (52\%) и эмпатия (45\%). Реже проявляется интерес к людям (36\%), и менее других оказывается развитой способность к пониманию другого человека $(23 \%)$.

Выявлено, что высокий уровень чувствительности к человеку создает благоприятные предпосылки для принятия позиции ненасилия (63\%), тогда как при низкой чувствительности позиция ненасилия практически не принимается (3\%). При низком уровне чувствительности к человеку студенты чаще принимают либо позицию невме- 
шательства (59\%), либо позицию принуждения (52\%). При высокой чувствительности к человеку процент испытуемых, принимающих позицию невмешательства или принуждения, значительно ниже и составляет 19 и $25 \%$ соответственно.

Полученные результаты могут быть использованы в процессе профессиональной подготовки студентов - будущих специалистов сферы психолого-педагогического сопровождения, а также в процессе разработки специальных программ по целенаправленному формированию у них способности к ненасильственному взаимодействию.

\section{СПИСОК АИТЕРАТУРЫ}

Андреева, Г. И. (2006) Эмоциональный интеллект: исследование феномена // Вопросы психологии. № 3. С. 78-86.

Бакурова, О. Н. (2015) Чувствительность к проблеме: психологические подходы к определению и изучению // Вестник Калужского университета. № 3 (28). С. 82-90.

Бодалев, А. А. (1982) Восприятие и понимание человека человеком. М. : Изд-во Моск. ун-та. 200 с.

Гаврилова, Т. П. (1974) Экспериментальное изучение эмпатии у детей младшего и среднего школьного возраста // Вопросы психологии. № 5. С. 107-114.

Аорошенко, Т. В. (2007) Исследование эмпатического профиля личности будущих психологов // Психологическая наука и образование. № 2. С. 42-49.

Есманская, Н. Е. (2007) Развитие психологической проницательности студентов-психологов посредством психологического анализа персонажей художественной литературы // Вестник Тамбовского университета. Серия: Гуманитарные науки. № 1 (45). С. 274-277.

Зудилина, И. Ю. (2014) Особенности интеракции у студентов различных социально-психологических типов дичности // Известия Самарской государственной сельскохозяйственной академии. № 2. С. 53-56.

Ильин, Е. П. (2013) Психология помощи. Альтруизм, эгоизм, эмпатия. СПб. : Питер. 304 с.

Кузнецова, Е. Н. (2010) Интерес к человеку как ценностное основание педагогического взаимодействия // Известия Российского государственного педагогического университета им. А. И. Герцена. № 121. С. 124-127.

Ааверычева, И. Г. (2013) Влияние эмпатии на проявления альтруизма и эгоизма // Известия Российского государственного педагогического университета им. А. И. Герцена. № 160. C. 65-74.

Маралов, В. Г., Малышева, Е. Ю., Маралова, Т. П., Перченко и др. (2013) Развивающаяся личность в зеркале угроз / под ред. В. Г. Маралова. Череповец : ФГБОУ ВПО ЧГУ. 144 с.

Маралов, В. Г., Маралова, Т. П. (2009) Мировоззренческие установки и сензитивность к человеку у студентов - будущих психологов // Ауховно-нравственное воспитание подрастающих поколений / отв. ред. А. Г. Козлова, В. Г. Маралов, М. С. Гаврилова. СПб. : 67 гимназия Verba Magistri. 450 c. С. $183-190$.

Маралов В. Г., Ситаров В. А. (2016) Психолого-педагогические условия формирования ненасильственного отношения к другим людям (на примере студенческой молодежи) // Знание. Понимание. Умение. № 2. С. 246-258. DOI: 10.17805/zpu.2016.2.22

Маралов В. Г., Ситаров В. А. (2017) Характеристика позиций взаимодействия как форм выражения ценностей принуждения и ненасилия // Знание. Понимание. Умение. № 1. С. 131-146. DOI: $10.17805 /$ zpu.2017.1.9

Маралов, В. Г., Ситаров, В. А. (2018) Разработка диагностического опросника по выявлению позиций взаимодействия у студентов - будущих специалистов сферы психолого-педагогического сопровождения // Знание. Понимание. Умение. №1. С. 167-177. DOI: 10.17805/ zpu.2018.1.13

Мерлин, В. С. (1964) Очерк теории темперамента. М. : Просвещение. 304 с. 
Минияров, В. М. (2000) Психология семейного воспитания (диагностико-коррекционный аспект). М. : Московский психолого-социальный институт ; Воронеж : Издательство НПО «MOAЭK». $256 \mathrm{c}$.

Писарев, А. Е., Зиновьева, Е. В., Костромина, С. Н. (2016) Взаимосвязь свойств личности начинающих психологов-консультантов с оценкой клиентов и их проблемных ситуаций // Научные исследования выпускников факультета психологии СПбГУ. Т. 4. С. 155-161.

Роджерс, К. (2002) Эмпатия // Психология мотивации и эмоций / под ред. Ю. Б. Гиппенрейтер, М. В. Фаликман. М. : ЧеРо ; НОУ Моск. психол.-соц. ин-т. 750 с. С. 428-430.

Сиволобова, И. В. (2002) Формирование у подростков ценностной ориентации на человека в детских общественных объединениях : дис. ... канд. пед. наук. Волгоград. 219 с.

Стрелкова, $\Lambda$. П. (1987) Психологические особенности развития эмпатии у дошкольников : дис. ... канд. психол. наук. М. 218 с.

Хекхаузен, Х. (2003) Мотивация и деятельность. СПб. : Питер ; М. : Смысл. 860 с. $512 \mathrm{c.}$

Шевандрин, Н. И. (1998) Психодиагностика, коррекция и развитие личности. М. : Владос.

Юсупов, И. М. (1995) Психология эмпатии (теоретические и прикладные аспекты) : дис. ... А-ра психол. наук. СПб. 252 с.

Fleck-Henderson, A. (1996) Ethical sensitivity: a theoretical and empirical : Dis. (PhD). The Fielding Institute.

Maralov V. G., Sitarov V. A. (2018) Person-oriented irritability, social and educational stereotypes as factor of adopting controlling or non-aggressive position by students // International Journal of Pharmaceutical Research and Allied Sciences. T. 7. № 2. C. 74-85.

Patterson, D. M. (2001) Causal effects of regulatory, organizational and personal factors on ethical sensitivity // Journal of Business Ethics. Vol. 30. № 2. P. 123-159.

Rest, J. R. (1986) Moral development: Advances in research and theory. N. Y.: Praeger. 241 p.

Salovey, P., Mayer, D. (1990) Emotional intelligence // Imagination, Cognition and Personality. Vol. 9. P. 185-211.

Weaver, K. (2005) Analysis of the concert of ethical sensitivity : Thesis (Ph.D.). University of Alberta.

Wittmer, D. P. (1993) Ethical sensitivity and managerial decision-making: an experiment : Dis. (PhD). Syracuse University.

Аата поступления: 12.06 .2018 г.

INFLUENCE OF HUMAN-SUSCEPTIBILITY

ON STUDENTS ASSUMING INTERACTION POSITIONS

\section{G. MARALOV \\ CHEREPOVETS STATE UNIVERSITY \\ L. V. ROMANYUK \\ MOSCOW UNIVERSITY FOR THE HUMANITIES}

The paper analyses the psychological peculiarities of the influence of susceptibility to human on students assuming interaction positions: coercion, manipulation, non-coercion, and non-interference. The issue is acute due to the significance of revealing factors, mechanisms and conditions creating the ability to interact with people in a non-coercive manner among students who specialise in psychological and pedagogical accompaniment.

The analysis is based on the survey results revealing the levels of manifestation of the interaction and human-susceptibility positions. The authors used methods of mathematical data processing, including the ?* criterion - the Fisher angular transformation.

The research was conducted in 2018 featuring 118 psychology and pedagogy students at Moscow University for the Humanities and Cherepovets State University, the respondents' average age being 19.5 years old. 
It was established that the students with a high level of human-susceptibility assume the non-coercion position ( 63 per cent) more often than the coercion position ( 25 per cent) or the non-interference position (19 per cent). Whereas the students whose human-susceptibility level is low tend to assume the non-interference position more often ( 59 per cent), as well as the position of coercion ( 52 per cent); but they do not normally use the position of non-coercion ( 3 per cent). The manipulation position did not prove to be substantially connected to the levels of human-susceptibility.

The authors draw a conclusion on the importance of instilling human-susceptibility in students as a factor contributing to a person assuming the non-coercion position. The achieved results can be used in development of special programmes on purposeful instilling the ability to interact in a non-coercive manner in students who specialise in psychological and pedagogical accompaniment.

Keywords: human-susceptibility; interest in human; empathy; understanding; help; coercion position; manipulation position; non-coercion position; non-interference position; students

\section{REFERENCES}

Andreeva, G. I. (2006) Emotsional'nyi intellekt: issledovanie fenomena. Voprosy psikbologii, no. 3, pp. 78-86. (In Russ.).

Bakurova, O. N. (2015) Chuvstvitel'nost' k probleme: psikhologicheskie podkhody k opredeleniiu i izucheniiu. Vestnik Kaluzbskogo universiteta, no. 3 (28), pp. 82-90. (In Russ.).

Bodalev, A. A. (1982) Vospriiatie i ponimanie cheloveka chelovekom. Moscow, Izd-vo Mosk. un-ta. 200 p. (In Russ.).

Gavrilova, T. P. (1974) Eksperimental'noe izuchenie empatii u detei mladshego i srednego shkol'nogo vozrasta. Voprosy psikbologii, no. 5, pp. 107-114. (In Russ.).

Doroshenko, T. V. (2007) Issledovanie empaticheskogo profilia lichnosti budushchikh psikhologov. Psikbologicheskaia nauka i obrazovanie, no. 2, pp. 42-49. (In Russ.).

Esmanskaia, N. E. (2007) Razvitie psikhologicheskoi pronitsatel'nosti studentov-psikhologov posredstvom psikhologicheskogo analiza personazhei khudozhestvennoi literatury. Vestnik Tambovskogo universiteta. Issue: Gumanitarnye nauki, no. 1 (45), pp. 274-277. (In Russ.).

Zudilina, I. Iu. (2014) Osobennosti interaktsii u studentov razlichnykh sotsial'no-psikhologicheskikh tipov lichnosti. Izvestiia Samarskoi gosudarstvennoi sel'skokboziaistvennoi akademii, no. 2, pp. 53-56. (In Russ.).

Il'in, E. P. (2013) Psikbologiia pomoshchi. Al'truizm, egoizm, empatiia. St. Petersburg, Piter. 304 p. (In Russ.).

Kuznetsova, E. N. (2010) Interes k cheloveku kak tsennostnoe osnovanie pedagogicheskogo vzaimodeistviia. Izvestiia Rossiiskogo gosudarstvennogo pedagogicheskogo universiteta im. A. I. Gertsena, no. 121, pp. 124-127. (In Russ.).

Laverycheva, I. G. (2013) Vliianie empatii na proiavleniia al'truizma i egoizma. Izvestiia Rossiiskogo gosudarstvennogo pedagogicheskogo universiteta im. A. I. Gertsena, no. 160, pp. 65-74. (In Russ.).

Maralov, V. G., Malysheva, E. Iu., Maralova, T. P., Perchenko et al. (2013) Razvivaiushchaiasia lichnost'v zerkale ugroz / ed. by V. G. Maralov. Cherepovets, FGBOU VPO ChGU. 144 p. (In Russ.).

Maralov, V. G. and Maralova, T. P. (2009) Mirovozzrencheskie ustanovki i senzitivnost' k cheloveku u studentov - budushchikh psikhologov. In: Dukbovno-nravstvennoe vospitanie podrastaiushchikh pokolenii / ed. by A. G. Kozlova, V. G. Maralov and M. S. Gavrilova. St. Petersburg, 67 gimnaziia Verba Magistri. 450 p. Pp. 183-190. (In Russ.).

Maralov V. G. and Sitarov V. A. (2016) Psikhologo-pedagogicheskie usloviia formirovaniia nenasil'stvennogo otnosheniia $\mathrm{k}$ drugim liudiam (na primere studencheskoi molodezhi). Znanie. Ponimanie. Umenie, no. 2, pp. 246-258. DOI: 10.17805/zpu.2016.2.22 (In Russ.).

Maralov V. G. and Sitarov V. A. (2017) Kharakteristika pozitsii vzaimodeistviia kak form vyrazheniia tsennostei prinuzhdeniia i nenasiliia. Znanie. Ponimanie. Umenie, no. 1, pp. 131-146. DOI: 10.17805/zpu.2017.1.9 (In Russ.).

Maralov, V. G. and Sitarov, V. A. (2018) Razrabotka diagnosticheskogo oprosnika po vyiavleniiu pozitsii vzaimodeistviia u studentov - budushchikh spetsialistov sfery psikhologo-pedagogichesko- 
go soprovozhdeniia. Znanie. Ponimanie. Umenie, no. 1, pp. 167-177. DOI: 10.17805/zpu.2018.1.13 (In Russ.).

Merlin, V. S. (1964) Ocherk teorii temperamenta. Moscow, Prosveshchenie. 304 p. (In Russ.).

Miniiarov, V. M. (2000) Psikbologiia semeinogo vospitaniia (diagnostiko-korrektsionnyi aspekt). Moscow, Moskovskii psikhologo-sotsial'nyi institut ; Voronezh : Izdatel'stvo NPO MODEKИ. 256 p. (In Russ.).

Pisarev, A. E., Zinov'eva, E. V. and Kostromina, S. N. (2016) Vzaimosviaz' svoistv lichnosti nachinaiushchikh psikhologov-konsul'tantov s otsenkoi klientov i ikh problemnykh situatsii. Nauchnye issledovaniia vypusknikov fakul'teta psikbologii SPbGU, vol. 4, pp. 155-161. (In Russ.).

Rodzhers, K. (2002) Empatiia. In: Psikbologiia motivatsii $i$ emotsii / ed. by Iu. B. Gippenreiter and M. V. Falikman. Moscow, CheRo ; NOU Mosk. psikhol.-sots. in-t. 750 p. Pp. 428-430. (In Russ.).

Sivolobova, I. V. (2002) Formirovanie u podrostkov tsennostnoi orientatsii na cheloveka $v$ detskikb obshchestvennykb ob'edineniiakb : Dis. ... Candidate of Pedagogy. Volgograd. 219 p. (In Russ.).

Strelkova, L. P. (1987) Psikhologicheskie osobennosti razvitiia empatii u doshkol' nikov: Dis. ... Candidate of Psychology. Moscow. 218 p. (In Russ.).

Khekkhauzen, Kh. (2003) Motivatsiia $i$ deiatel'nost'. St. Petersburg, Piter ; Moscow, Smysl. 860 p. (In Russ.).

Shevandrin, N. I. (1998) Psikbodiagnostika, korrektsiia i razvitie lichnosti. Moscow, Vlados. 512 p. (In Russ.).

Iusupov, I. M. (1995) Psikbologiia empatii (teoreticheskie $i$ prikladnye aspekty) : Dis. ... Doctor of Psychology. St. Petersburg. 252 p. (In Russ.).

Fleck-Henderson, A. (1996) Ethical sensitivity: a theoretical and empirical : Dis. (PhD). The Fielding Institute.

Maralov V. G. and Sitarov V. A. (2018) Person-oriented irritability, social and educational stereotypes as factor of adopting controlling or non-aggressive position by students. International Journal of Pharmaceutical Research and Allied Sciences, vol. 7, no. 2, pp. 74-85.

Patterson, D. M. (2001) Causal effects of regulatory, organizational and personal factors on ethical sensitivity. Journal of Business Ethics, vol. 30, no. 2, pp. 123-159.

Rest, J. R. (1986) Moral development: Advances in research and theory. N. Y., Praeger. 241 p.

Salovey, P. and Mayer, D. (1990) Emotional intelligence. Imagination, Cognition and Personality, vol. 9, pp. 185-211.

Weaver, K. (2005) Analysis of the concert of etbical sensitivity : Thesis (Ph.D.). University of Alberta.

Wittmer, D. P. (1993) Etbical sensitivity and managerial decision-making: an experiment : Dis. (PhD). Syracuse University.

Submission date: 12.06 .2018$.

Маралов Владимир Георгиевич - доктор психологических наук, профессор кафедры психологии Череповецкого государственного университета. Адрес: 162600, Россия, г. Череповец, пр-т Иуначарского, д. 5. Тел.: +7 (921) 252-40-57. Эл. адрес: vgmaralov@yandex.ru

Романюк Аариса Валерьевна - доктор педагогических наук, профессор, проректор по научной работе Московского гуманитарного университета. Адрес: 111395, Россия, г. Москва, ул. Юности, д. 5. Тел.: +7 (495) 374-58-81. Эл. адрес: lromanyuk@mosgu.ru

Maralov Vladimir Georgiyevich, Doctor of Psychology, Professor, Department of Psychology, Cherepovets State University. Postal address: 5, Lunacharskogo Ave., Cherepovets, Russian Federation, 162600. Tel.:+7 (921) 252-40-57. E-mail:vgmaralov@yandex.ru

Romanyuk Larisa Valeryevna, Doctor of Pedagogy, Professor, Vice-rector for Academic Work, Moscow University for the Humanities. Postal address: 5, Yunosti St., Moscow, Russian Federation, 111395. Tel.: +7 (495) 374-58-81. E-mail: 1romanyuk@mosgu.ru 